\section{BIRD-LIFE AT THE SOUTH ORKNEY ISLANDS.}

DURING the years 1903 and 1904 the Scottish National Antarctic Expedition made important ornithological researches in the icy regions of the far south, and also at the ren?arkably remote island of Diego Alvarez, otherwise Gough Island, in the South Atlantic. In both, extensive collections of birds were made, which were recently described in the pages of the Ibis.

The main scene of these investigations was at the South Orkneys, a group of more than a dozen islands lying some 600 miles south-east of the Falklands, and which, though discovered so long ago as $182 \mathrm{I}$, had remained among the least known lands within the South Polar seas. The climate of this archipelago, in spite of its comparatively low latitude $\left(60^{\circ}-6 \mathrm{r}^{\circ} \mathrm{S}\right.$.), is essentially polar, the summer temperature being much the same as in regions $10^{\circ}$ further south, while in winter as many as $72^{\circ}$ of frost were registered.

On Laurie Island, the second largest (30 square miles) of the group, eleven months were spent by the expedition, including the winter of 1903 . During this period a number of interesting and valuable observations were made relating to the native birds (some of them little known), their habits, migrations, nidification, and geographical distribution; while the collections formed enabled me to describe phases previously quite unknown in the plumage of several rare species, and also included the eggs of forms never before obtained.

Only a few birds essayed to winter, but on the return of spring marvellous numbers arrived to spend the summer and to rear their young.

The penguins were by far the most numerous, and were of four kinds. The Adélie (Pygoscelis adéliae) was the most abundant, its numbers being estimated at not less than five millions; the ringed $(P$. antarctica), which was previously regarded as nowhere common, evidently has its metropolis at the South Orkneys, for at least one million nested on Laurie Island alone; while the gentoo ( $P$. papua) was less numerous, since it here nears the southern limit of its range. Another species, the macaroni penguin (Catarrhactes chrysolophus), was found in very small numbers, but it probably breeds somewhere in the archipelago. The three first mentioned species of penguin nested in great " rookeries," some of which contained several millions of inhabitants, and extended as a broad belt for two or three miles over elevated plateaux bordering the

sea. Their nests were constructed of small stones deliberately collected one by one, and, on an average, there was a nest to each square yard of the area occupied.

Life in these great bird cities was not altogether a happy one. The penguins are ill-natured and pugnacious birds, and woe betide the citizen who trespassed upon the domain of his neighbours, or the poor unfortunate who had not secured a mate and ventured within the precincts of the rookery. Then the bills of all the birds around were turned against the intruders, and a fearful commotion ensued which generally resulted in a free fight all round, each pair of birds attacking their neighbour, and ended in the rookery becoming a veritable pandemonium, rendered hideous by the harsh screeches of hundreds of thousands of voices. Such squabbles and their consequences, however, were mere trifles when compared with two scourges ever present among the sitting birds. Foremost among these were the savage giant potrels, the greatest of feathered ruffians, which wandered in numbers through. out the community gorging themselves to repletion on the eggs and young forcibly taken from the brooding penguins. The second terror was the Antarctic skua, many of which hovered overhead, like so many harpies, and incessantly swooped down to snatch the same treasures from the much persecuted parents.

When courting, as one of the pictures shows, the enamoured ones elevate their bills and utter their far from musical love songs. They do this in unison, moving their heads backwards and forwards or waving them from side to side all the while.

Next to the penguins, the petrels were the most numerous of the bird inhabitants of the island. Of these, eight species were present, most of which were nesting on the sea cliffs, or on the steep screes springing from their bases. On such sites was discovered the egg of the Cape petrel or pigeon (Daption capensis), a bird well known to voyagers for more than two hundred years, yet one which had hitherto succeeded in hiding its plain white egg from the gaze of oologists. Many of the eggs of this bird were found on the ledges of the cliffs, but collecting them was not a pleasant pursuit, for these birds, like some others of their order have the power of squirting a quantity of evilsmelling oil at intruders, making good marksmanship at 8 feet. Fortunately the giant petrel (Ossifraga gigantea), a bird as big as a goose, did not practise this art. otherwise the taking of its egg would indeed have been an ordeal. This species, too, sat close, and when pushed off its nest, which consisted of a great heap of stones, it vomited the 
regular scavengers, to which the dung of seals did not come amiss.

The chief food of the millions of penguins and tens of thousands of petrels was the opossum shrimp (Euphausia antarctica), and when one remembers the vast numbers of this little crustacean consumed daily by the birds on Laurie Island alone, one can only compare their numbers in the sea with the grains of sand upon its beaches.

The Scottish National Antarctic Expedition is to be heartily congratulated on the excellence and importance of its ornithological work. Mr. Bruce, the leader of the expedition, has presented a complete set of the South Orkneys inquiry, it had been ascertained that a certain proportion of the amount required for bulluing and equipping such a tank would be guaranteed by private firms and public bodies. It was obvious that the condition of shipbuilding at the time the proposals were formerly made did not favour the movement, and it was therefore decided to suspend action. Since the scheme was first mooted, additional private experimental tanks had been either laid down or projected by some of the great shipbuilding firms of the country. Such tanks as these, however, could never supply the need that existed for pure research. The council had therefore decided to call together

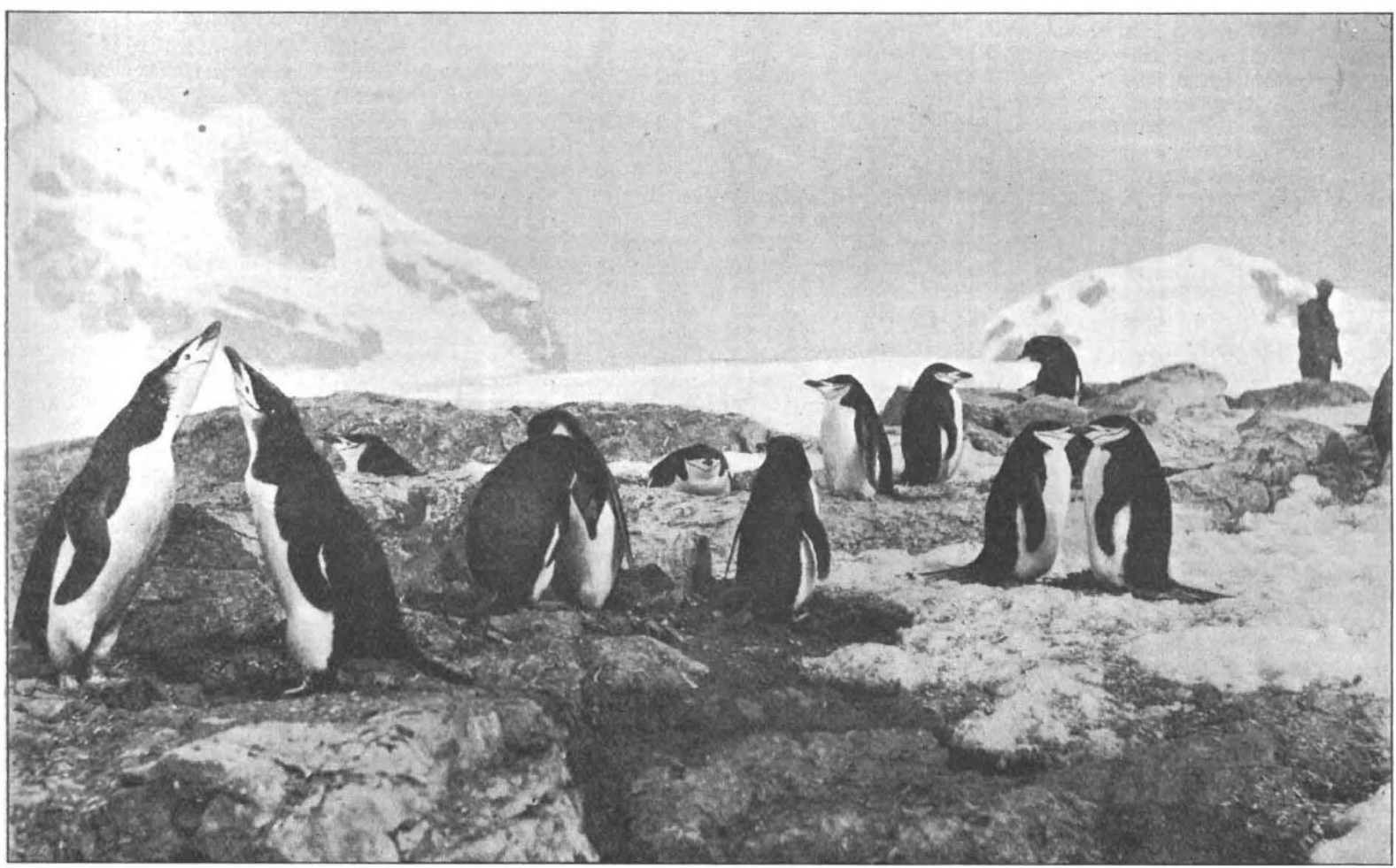

FIG. 2,-Ringed Penguins courting (Brown's Bay).

and other birds collected during the voyage of the Scotia to the Roval Scottish Museum, Edinburgh.

For the loan of the blocks from which the pictures have been reproduced we are indebted to the editors of the Ibis.

Wm. Eagle Clarke.

\section{INSTITUTION OF NAVAL ARCHITECTS.}

THE annual general meeting of the Institution of Nava Architects was held last week, commencing Wednesday, April 4, and being continued over the following Thursday and Friday. A full programme of twelve papers had been prepared by the secretary, Mr. R. W. Dana. The subjects dealt with were of various interest, vessels fitted with internal combustion motors occupying a good deal of attention. There was, however, no paper on the steam turbine.

On members assembling on the morning of Wednesday, the president, the Right Hon, the Earl of Glasgow, took the chair, and after the usual formal business had been transacted, proceeded to read his annual address. $\mathrm{He}$ referred to the launch of the large line-of-battle ship Dreadnought, and gave certain figures relating to the Navy Estimates. Reference was made to the proposed experimental tank at Bushy. There had been, he said, a general appeal to members of the institution for financial support, but, as the result of preliminary

NO. 1902 , VOL. 73$]$ the committee that had the matter in hand, and ascertiin the views of the members on the present position of the scheme, and the prospects of its being brought to a successful conclusion. Should the shipowners of the country be unwilling to subscribe the comparatively small amount needed to build, equip, and maintain such a tank, nothing would remain but to abandon the scheme and dissolve the committee. The president hoped, however, that, before such a conclusion was reached, a fresh effort might be successfully made to carry out upon scientific lines a work of vital importance to the development of naval architecture in this country.

The first paper read was a contribution by Admiral C. C. P. FitzGerald, the subject being the new scouts recently designed for the Royal Navy. Details of these vessels were given, and the subject of naval scouting was discussed both from the strategical and tactical point of view. A discussion followed, in which several naval officers took part, and it was pointed out that the scouts were analogous to the old 36-gun frigates, these being the most powerful ships that could be detached from the fleet without weakening the line of battle.

Sir Edward J. Reed next gave an account of the vessels he had designed for service in the colonies. They were of various descriptions, consisting of both screw and paddle boats, the former being of the ordinary or of the tunnelscrew type, whilst both stern-wheel and side-wheel boats were used on the shallow waters of colonial rivers. 